in vivo $33: 815-819(2019)$

doi:10.21873/invivo.11544

\title{
Combined EGFR/ALK Expression Analysis in Laryngeal Squamous Cell Carcinoma
}

\author{
ANASTASIA POLITI ${ }^{1}$, EVANGELOS TSIAMBAS ${ }^{2}$, NICHOLAS S. MASTRONIKOLIS ${ }^{3}$, \\ DIMITRIOS PESCHOS ${ }^{4}$, IOANNIS ASPROUDIS ${ }^{5}$, EFTHYMIOS KYRODIMOS ${ }^{6}$, \\ ILIANNA E. ARMATA ${ }^{7}$, ARISTEIDIS CHRYSOVERGIS ${ }^{6}$, ASIMAKIS ASIMAKOPOULOS ${ }^{8}$, \\ VASILEIOS S. PAPANIKOLAOU ${ }^{6}$, ANNA BATISTATOU ${ }^{9}$ and VASILEIOS RAGOS ${ }^{10}$ \\ ${ }^{1}$ Department of Oncology, Medical School, University of Ioannina, Ioannina, Greece; \\ ${ }^{2}$ Department of IHC \& Molecular Biology, 401 GAH, Athens, Greece; \\ ${ }^{3}$ ENT Department, Medical School, University of Patras, Patras, Greece; \\ ${ }^{4}$ Department of Physiology, Medical School, University of Ioannina, Ioannina, Greece; \\ ${ }^{5}$ Department of Ophthalmology, Medical School, University of Ioannina, Ioannina, Greece; \\ ${ }^{6} 1$ ST ENT Department, Hippokration Hospital, National and Kapodistrian University of Athens, Athens, Greece; \\ ${ }^{7}$ Medical School, Cambridge University Hospital, Cambridge, U.K.; \\ ${ }^{8}$ ENT Department, Luxembourg Hospital Center, Luxembourg, Luxembourg; \\ ${ }^{9}$ Department of Pathology, Medical School, University of Ioannina, Ioannina, Greece; \\ ${ }^{10}$ Department of Maxillofacial, Medical School, University of Ioannina, Ioannina, Greece
}

\begin{abstract}
Background/Aim: Epidermal growth factor receptor (EGFR) acts as an oncogene in malignancies. Our aim was to examine the role of combined EGFR/ anaplastic lymphoma kinase (ALK) expression as molecular markers in laryngeal squamous cell carcinoma (LSCC) patients. Materials and Methods: Fifty $(n=50)$ tissue sections derived from twenty-five $(n=25)$ primary LSCCs were analyzed by immunohistochemistry (IHC). Results: EGFR overexpression was observed in 17/25 (68\%) cases. Concerning ALK, 23/25 (92\%) demonstrated low expression. EGFR expression was associated with grade $(p=0.049)$, whereas ALK expression was correlated with stage $(p=0.048)$. ALK overexpression was detected at advanced-stage EGFR-positive cases. A biphasic EGFR protein expression pattern was observed in five $(n=5)$ LSCC cases, whereas ALK expression was stable in all cases. Conclusion: EGFR overexpression is frequently observed in LSCC combined with low ALK expression.
\end{abstract}

This article is freely accessible online.

Correspondence to: Evangelos Tsiambas, Cytopathologist, MD, MSc, PhD, Lecturer elect in Molecular Cytology, Medical School, National and Kapodistrian University of Athens, 17 Patriarchou Grigoriou E' Street, Ag. Paraskevi, 15341 Athens, Greece. Tel: +306946939414, e-mail: tsiambasecyto@yahoo.gr

Key Words: Carcinoma, larynx, EGFR, ALK.
LSCC patients with EGFR/ALK protein overexpression should be eligible for targeted therapeutic strategies.

Molecular analyses in solid malignancies - including laryngeal squamous cell carcinomas (LSCC) - have shown that upregulation of specific growth factor receptors critically destabilize the cell micro-environment inducing signal transduction from the membrane to the nucleus (1). Among these molecules, epidermal growth factor receptor (EGFR) plays a crucial role in this process. The EGFR (other names include: $E R B B, E R B B 1$, or $H E R 1$ ) gene is located on the short (p) arm of chromosome 7 at position 12 (cytogenetic chr band $7 p 12.1)$ (2). The protein encoded by the corresponding gene acts as a transmembrane glycoprotein. It is a member of the v-erb-b2 erythroblastic leukemia viral oncogene (ErbB)/human epidermal receptor (HER) family of receptor tyrosine kinases, that includes also other three cell membrane receptor tyrosine kinases: HER2/c-neu (ERBB2), HER3 (ERBB3) and HER4 (ERBB4). Three main EGFR depended pathways have been already identified including the PI3K-AKT-PTEN-mTOR, the RAS-(B) RAF-MEK-ERK/MAPK and also the IL6-JAK1/2STAT3 (3). Concerning LSCC, a subset of patients exhibits EGFR activating mutations (approximately 10-30\%) and also gene amplification (approximately 10-35\%) leading to protein overexpression $(4,5)$. Similarly, deregulation of anaplastic lymphoma kinase (ALK) seems to be a novel marker in handling LSCC patients with EGFR aberrant expression. ALK gene is located at chromosome 2 (2p23 band) encoding a protein which acts as a transmembrane receptor tyrosine kinase 
(6). A fusion between ALK and nucleophosmin (NPM) gene located at $5 \mathrm{q} 35$ has been identified as a $\mathrm{t}(2 ; 5)$ chromosomal translocation. Pathological entities demonstrating this genetic signature are anaplastic large-cell lymphoma (an aggressive non-Hodgkin lymphoma type), neuroblastoma, and also nonsmall-cell lung carcinoma (NSCLC) $(7,8)$. In the current study, EGFR and ALK protein expression levels were co-analyzed in LSCCs tissue sections and were correlated with the corresponding clinico-histological features.

\section{Materials and Methods}

Study group. For the purposes of this study, fifty $(\mathrm{n}=50)$ archival, formalin-fixed and paraffin-embedded tissue blocks of surgically resected, histologically confirmed primary LSCCs $(n=25)$ were used (two tissue sections per case). The specimens were derived from twenty-one $(n=21)$ male and four $(n=4)$ female patients, who were all smokers without a positive DNA test or a clear history of Human Papilloma Virus (HPV) persistent infection. The hospital ethics committee consented to the use of these tissues in the Department of Pathology, Medical School, University of Ioannina, Ioannina, Greece for research purposes, according to World Medical Association Declaration of Helsinki guidelines (2008). According to their clinical status, patients were treated by chemotherapy (C-cisplatin based), radiotherapy $(\mathrm{R})$, or combined $\mathrm{CR}$-regimens. The tissue samples were fixed in $10 \%$ neutral-buffered formalin. Hematoxylin and eosin (H\&E)-stained slides of the corresponding samples were reviewed for confirmation of histopathological diagnoses. All lesions were classified according to the histological typing criteria of World Health Organization (WHO) (9). Clinicopathological data of the examined cases are demonstrated in Table I.

Antibodies and immunohistochemistry assay (IHC). Ready-to-use EGFR monoclonal mouse antibody (clone 31G7-Zymed/InVitrogen, San Francisco, CA, USA) recognizing the extracellular domain of EGFR protein, but not reacting with other erbB receptors was used. Additionally, monoclonal mouse anti-ALK (CD246) antibody (clone ALK-1, DAKO, Glostrup, Denmark; dilution at 1:100, 30 min at $25^{\circ} \mathrm{C}$ ) was applied.

IHC for the markers' expression was carried out on 4- $\mu$ m serial sections of the corresponding tissue blocks. The corresponding slides were deparaffinized, rehydrated and enzyme digested for 10 min at $37^{\circ} \mathrm{C}$. The EnVisionTM+ ${ }^{+}$, Dako) detection system was used in the following detection steps. Blocking solution was applied to the slides for $10 \mathrm{~min}$, followed by incubation for $1 \mathrm{~h}$ with the antibodies at room temperature. Following incubation with the secondary antibody for $10 \mathrm{~min}$, diaminobenzidine-tetrahydroclorideDAB $(0.03 \%)$ containing $0.1 \%$ hydrogen peroxide was applied as a chromogen and incubated for $5 \mathrm{~min}$. Sections were counterstained, dehydrated and cover-slipped. For negative control slides, the primary antibody was omitted. IHC protocol was performed by the use of an automated staining system (I 6000 - Biogenex, San Ramon, CA, USA). Membranous and sub-membranous staining patterns were considered acceptable for EGFR essential expression, and cytoplasmic/perinuclear staining for ALK. Microscopically normal appearing laryngeal epithelia tissue sections expressing Bcl2 protein were considered as positive controls. Protein expression levels were evaluated based on a staining score system. According to this, the examined cases were classified as follows: Score 0: no staining or membrane/cytoplasmic staining in $<10 \%$ of tumor cells; Score 1+: faint membrane/cytoplasmic staining in $>10 \%$ of tumor cells; Score 2+: weak or moderate complete membrane/ cytoplasmic staining in $>10 \%$ of tumor cells and Score $3+$ : strong, complete membrane/ cytoplasmic staining in $>10 \%$ of tumor cells. Scores of 0 and $1+$ were considered as negative for EGFR/ALK expression while Scores $2+/ 3+$ as positive (overexpression), respectively.

Statistical analysis. Descriptive statistics were performed. Associations between variables including protein expression levels, and clinicopathological parameters such as gender, tumor grade and stage were performed using Pearson Chi square test $\left(\chi^{2}\right)$ estimated along with its 99\%CI and Spearman coefficient (SPSS v20 (SPSS Inc, Chicago, IL, USA). Two-tailed $p$-values $\leq 0.05$ were considered statistically significant. Results and $p$-values are described in Table I.

\section{Results}

According to IHC evaluation guidelines, the examined cases demonstrated different EGFR/ALK expression levels. EGFR overexpression (Score $2+/ 3+$, moderate to high expression levels) was observed in 17/25 (68\%) LSCC tissue sections, whereas the rest of them demonstrated low expression (Score $1+)$. EGFR overall expression was correlated to the gender of the examined patients $(p=0.007)$. Concerning ALK expression, the majority of the examined tissue sections $(23 / 25-92 \%)$ demonstrated low expression levels. EGFR expression was associated with the grade $(p=0.049)$, whereas ALK expression was correlated with the stage of the examined malignancies $(p=0.048)$. No statistical significance was observed correlating EGFR with ALK overall expression $(p=0.133)$. Interestingly, ALK overexpression was detected mainly in EGFR positive cases with advanced stage cancer. Biphasic (score 1+/2+) EGFR protein expression pattern was observed in five $(n=5)$ LSCC cases. Score $2+$ was considered prominent for categorizing these cases in protein analysis. In contrast to EGFR partial biphasic expression, ALK expression pattern was stable (homogenous) in all examined cases (Figure 1).

\section{Discussion}

Identification of specific gene deregulation mechanisms leads to optimal management of patients suffered by solid malignancies. Concerning LSCC, anti-EGFR targeted therapeutic strategies based on monoclonal antibodies (mAbs) or tyrosine-kinase inhibitors (TKIs) represent very promising approaches in modern oncology $(10,11)$. EGFR overexpression - due to gene amplification or point mutations - is frequently observed in LSCC cases analyzed by IHC $(12,13)$. In our protein analysis, overexpression of the marker was correlated with the grade of the examined cases. Another study has shown similar association combined, also, with overall advanced disease characteristics, including stage and metastasizing potential leading to poor prognosis (14). 


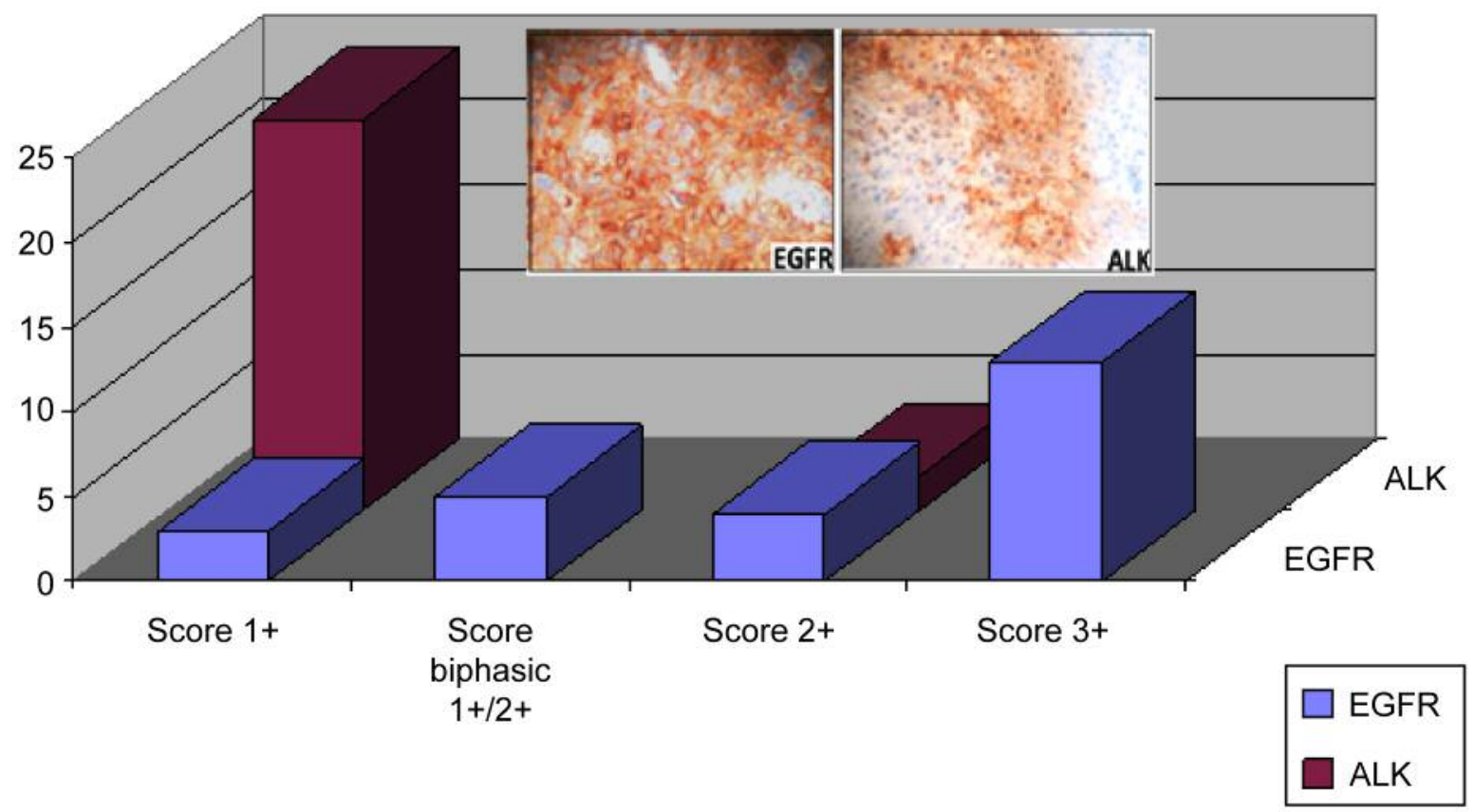

Figure 1. Histogram showing the EGFR and ALK expression patterns (Score 1+/2+/3). Biphasic expression (Score 2+/1+) was reported only for EGFR in some cases. Inside plates: overexpression of EGFR and ALK assayed by IHC (Score 2+/3+). Note the membranous/cytoplasmic staining pattern (DAB chromogen, original magnification 100x).

Table I. Clinicopathological parameters and total EGFR/ALK protein expression results.

\begin{tabular}{|c|c|c|c|c|c|c|}
\hline \multirow[t]{2}{*}{ Clinicopathological parameters } & \multicolumn{2}{|c|}{ EGFR } & \multirow[t]{2}{*}{$p$-Value } & \multicolumn{2}{|c|}{ ALK } & \multirow[t]{2}{*}{$p$-Value } \\
\hline & $\mathrm{OE}$ & LE & & $\mathrm{OE}$ & LE & \\
\hline $\operatorname{LSCC}(n=25)$ & $17 / 25(68 \%)$ & $8 / 25(32 \%)$ & & $2 / 25(8 \%)$ & $23 / 25(92 \%)$ & \\
\hline Gender & & & 0.007 & & & 0.723 \\
\hline Male $(n=21)$ & $16 / 25(64 \%)$ & $5 / 25(20 \%)$ & & $2 / 25(8 \%)$ & $19 / 25(76 \%)$ & \\
\hline Female $(n=4)$ & $1 / 25(4 \%)$ & $3 / 25(12 \%)$ & & $0 / 25(0 \%)$ & $4 / 25(16 \%)$ & \\
\hline Grade & & & 0.049 & & & 0.898 \\
\hline $1(\mathrm{n}=7)$ & $6 / 25(24 \%)$ & $1 / 25(4 \%)$ & & $2 / 25(8 \%)$ & $5 / 25(20 \%)$ & \\
\hline $2(n=17)$ & $9 / 25(36 \%)$ & $8 / 25(32 \%)$ & & $0 / 25(0 \%)$ & $17 / 25(68 \%)$ & \\
\hline $3(n=1)$ & $1 / 25(4 \%)$ & $0 / 25(\%)$ & & $0 / 25(0 \%)$ & $1 / 25(4 \%)$ & \\
\hline Stage & & & 0.378 & & & 0.048 \\
\hline I $(n=7)$ & $6 / 25(24 \%)$ & $1 / 25(4 \%)$ & & $0 / 25(0 \%)$ & $7 / 25(28 \%)$ & \\
\hline II $(n=15)$ & $10 / 25(40 \%)$ & $5 / 25(20 \%)$ & & $2 / 25(8 \%)$ & $13 / 25(52 \%)$ & \\
\hline III $(n=3)$ & $2 / 25(8 \%)$ & $1 / 25(4 \%)$ & & $0 / 25(0 \%)$ & $3 / 25(12 \%)$ & \\
\hline
\end{tabular}

OE: Over expression $(2+/ 3+)$; LE: low expression $(0 / 1+)$.

Interestingly, another study has concluded that the synergetic over activation of EGFR and hepatocyte growth factor tyrosine kinase receptor MET proto-oncogene, (c MET-gene locus: $7 q 31)$ is associated with poor survival especially in patients with glottis LSCC (15). Similarly, another LSSC study has evaluated the efficacy of ME22S agent, a novel EGFR/Met bispecific antibody using an in vitro and also a xenograft model
(16). The study has indicated that dual inhibition of EGFR and Met suppressed the invasion and growth potential of the corresponding LSCC cell cultures. They suggested that this dual action should be a modern approach in therapeutic strategies for the treatment of LSCC subsets of patients with specific molecular signatures. Concerning the EGFR protein expression in LSCC, a biphasic (membranous to cytoplasmic) 
pattern was observed in some cases. Intratumoral heterogeneity in EGFR protein expression -due to different genetic substratein LSCCs has been similarly detected by IHC (17). Another study co-analyzing EGFR at the DNA and protein levels has identified a correlation between cytoplasmic predominantly expression and gene amplification, especially in LSCCs derived from glottis (18). In contrast to this association, Ecadherin and not EGFR aberrant expression seems to be correlated with advance stage (distant high metastatic potential, poor prognosis) in LSCC (19).

ALK aberrant expression - due to its gene rearrangements (fusion or mutations) - is, in contrast to NSCLC, not a frequent event in $\operatorname{LSCC}(20,21)$. Low expression is common in these malignancies. In our protein analysis, only a small subset of specimens demonstrated overexpression of the marker. Concerning its inhibition strategies, ceritinib, crizotinib, alectinib and brigatinib have been developed and have been FDA approved as targeted agents $(22,23)$. Interestingly, a study analyzing in vitro (cell cultures, xenografts) the potential interaction between EGFR and ALK aberrant expression has shown that the induction of ALK acts as a novel mechanism of EGFR inhibitor resistance in these carcinomas (24). In fact, application of gefitinib in combination with ceritinib and brigatinib, induced ALK expression. In contrast to LSCC, specific HNSCC pathological entities demonstrate differences regarding ALK gene expression profiles. Controversial data have been published for ALK alterations in sarcomatoid HNSCC referring to its translocation $(25,26)$.

\section{Conclusion}

Assessment of ALK and EGFR aberrant protein expression due to gene deregulation (fusions/translocations, mutations, amplification) seem to be critical for applying targeted therapeutic regimens in subsets of LSCC patients with specific molecular aspects. Although ALK expression is mainly low in these malignancies, interaction between the two proteins composes a mechanism that modifies resistance to anti-EGFR targeted therapies. This observation influences also other HNSCCs, such as oral SCC. ALK inhibitors seem to induce the anti-tumor activity of EGFR inhibitors in these carcinomas by increasing ALK expression, especially through abolition of intermediate signalling transduction molecules, such as AKT activation (27).

\section{Conflicts of Interest}

The Authors declare no conflicts of interest regarding this study.

\section{Authors' Contributions}

Anastasia Politi: researcher; Evangelos Tsiambas researcher, paper writing; Nicholas S Mastronikolis: academic advisor; Dimitrios
Peschos: academic advisor; Ioannis Asproudis: academic advisor; Efthymios Kyrodimos: academic advisor, paper writing; Ilianna Armata: statistical analysis; Asimakis Asimakopoulos: academic advisor; Anna Batistatou: academic advisor; Vasileios Ragos: academic advisor; Aristeidis Chrysovergis: clinical advisor; Vasileios S Papanikolaou: clinical advisor.

\section{References}

1 Arteaga $\mathrm{Cl}$ : The epidermal growth factor receptor: from mutant oncogene in nonhuman cancers to therapeutic target in human neoplasia. J Clin Oncol 19: 32-40, 2001. PMID: 11560969.

2 Nicholson RI, Gee JM and Harper ME: EGFR and cancer prognosis. Eur J Cancer 37: S9-S15, 2001. PMID: 11597399.

3 Molina J and Adjei A: The Ras/Raf/MAPK pathway. J Thorac Oncol 1: 7-9, 2006. PMID: 17409820.

4 Ang KK, Berkey BA, Tu X, Zhang HZ, Katz R, Hammond EH, $\mathrm{Fu}$ KK and Milas L: Impact of epidermal growth factor receptor expression on survival and pattern of relapse in patients with advanced head and neck carcinoma. Cancer Res 62(24): 73507356, 2002. PMID: 12499279.

5 Boeckx C, Weyn C, Vanden Bempt I, Deschoolmeester V, Wouters A, Specenier P, Van Laer C, Van den Weyngaert D, Kockx M, Vermorken JB, Peeters M, Pauwels P, Lardon F and Baay M: Mutation analysis of genes in the EGFR pathway in Head and Neck cancer patients: implications for anti-EGFR treatment response. BMC Res Notes 7: 337-744, 2014. PMID: 24899223. DOI: $10.1186 / 1756-0500-7-337$

6 Mologni L: Inhibitors of the anaplastic lymphoma kinase. Expert Opin Investig Drugs 21: 985-994, 2012. PMID: 22612599. DOI: 10.1517/13543784.2012.690031

7 Iwahara T, Fujimoto J, Wen D, Cupples R, Bucay N, Arakawa T, Mori S, Ratzkin B and Yamamoto T: Molecular characterization of ALK, a receptor tyrosine kinase expressed specifically in the nervous system. Oncogene 14: 439-449, 1997. PMID: 9053841.

8 Shaw AT and Engelman JA: Ceritinib in ALK-rearranged nonsmall-cell lung cancer. N Engl J Med 370: 2537-2539, 2014. PMID: 24963575. DOI: 10.1056/NEJMc1404894

9 Barnes L, Eveson JW, Reichart P and Sidransky D: Pathology and Genetics: Head and Neck Tumours. WHO IARC Press, Lyon, Fr. pp. 118-130, 2005.

10 Cassell A and Grandis JR: Investigational EGFR-targeted therapies in HNSCC. Expert Opin Investig Drugs 19: 709-722, 2010. PMID: 20415598.

11 Chong CR and Janne PA: The quest to overcome resistance to EGFR-targeted therapies in cancer. Nat Med 19: 1389-1400, 2013. PMID: 24202392.

12 Moon C, Chae YK and Lee J: Targeting epidermal growth factor receptor in head and neck cancer: lessons learned from cetuximab. Exp Biol Med 235: 907-920, 2010. PMDI: 20562132.

13 Tsiambas E, Stavrakis I, Lazaris AC, Karameris A and Patsouris E: Evaluation of epidermal growth factor receptor gene and chromosome 7 alterations in squamous cell carcinoma of the larynx, using chromogenic in situ hybridization on tissue microarrays. J Laryngol Otol 121(6): 563-570, 2007. PMID: 16882359.

14 Kontić M, Milovanović J, Čolović Z, Poljak NK, Šundov Ž, Sučić A, and Pešutić-Pisac V: Epidermal growth factor receptor (EGFR) expression in patients with laryngeal squamous cell carcinoma. Err Arch Otorhinolaryngol 272(2): 401-405, 2015. PMID: 25294054. DOI: 10.1007/s00405-014-3323-9 
15 Jiang M, Zhang H, Xiao H, Zhang Z, Que D, Luo J, Li J, Mao B, Chen Y, Lan M, Wang G and Xiao H: High expression of cMet and EGFR is associated with poor survival of patients with glottis laryngeal squamous cell carcinoma. Oncol Lett 15(1): 931-939, 2018. PMID: 29391895. DOI: 10.3892/ol.2017.7356

16 Lee BS, Kim HJ, Hwang JW, Cheong KH, Kim KA, Cha HY, Lee JM and Kim CH: The dual inhibition of Met and EGFR by ME22S, a novel Met/EGFR bispecific monoclonal antibody, suppresses the proliferation and invasion of laryngeal cancer. Ann Surg Oncol 23(6): 2046-2053, 2016. PMID: 26812910. DOI: $10.1245 / \mathrm{s} 10434-015-5084-0$

17 Fujii S, Uryu H, Akashi K, Suzuki K, Yamazaki M, Tahara M, Hayashi R and Ochiai A: Clinical significance of KRAS gene mutation and epidermal growth factor receptor expression in Japanese patients with squamous cell carcinoma of the larynx, oropharynx and hypopharynx. Int J Clin Oncol 18(3): 454-463, 2013. PMID: 22441881.

18 Braut T, Krstulja M, Rukavina KM, Jonjić N, Kujundžić M, Manestar ID, Katunarić M and Manestar D: Cytoplasmic EGFR staining and gene amplification in glottic cancer: a better indicator ofEGFR-driven signaling? Appl Immunohistochem Mol Morphol 22(9): 674-680, 2014. PMID: 25279714. DOI: 10.1097/PAI.0000000000000014

19 Rodrigo JP, Martínez P, Allonca E, Alonso-Durán L, Suárez C, Astudillo A and García-Pedrero JM: Immunohistochemical markers of distant metastasis in laryngeal and hypopharyngeal squamous cell carcinomas. Clin Exp Metastasis 31(3): 317-325, 2014. PMID: 24370715. DOI: 10.1007/s10585-013-9630-5

20 Skoulidis F and Papadimitrakopoulou VA: Personalized medicine tackles clinical resistance: Alectinib in ALK-positive non-small cell lung cancer progressing on first-generation ALK inhibitor. Clin Cancer Res 22(21): 5177-5182, 2016. PMID: 27609840. DOI: 10.1158/1078-0432.CCR-16-1415

21 Zenali MJ, Weissferdt A, Solis LM, Ali S, Tang X, Mehran RJ, Wistuba II, Moran CA and Kalhor N: An update on clinicopathological, immunohistochemical, and molecular profiles of colloid carcinoma of the lung. Hum Pathol 46(6): 836-842, 2015. PMID: 25776025. DOI: 10.1016/j.humpath.2014.10.032
22 Yoshihara K, Wang Q, Torres-Garcia W, Zheng S, Vegesna R, Kim H and Verhaak RG: The landscape and therapeutic relevance of cancer-associated transcript fusions. Oncogene 34(37): 48454854, 2015. PMID: 25500544. DOI: 10.1038/onc.2014.406

23 Shroff GS, Benveniste MF, de Groot PM, Wu CC, Viswanathan C, Papadimitrakopoulou VA and Truong MT: Targeted therapy and imaging findings. J Thorac Imaging 32(5): 313-322, 2017. PMID: 28832416.

24 Ouyang X, Barling A, Lesch A, Tyner JW, Choonoo G, Zheng C, Jeng S, West TM, Clayburgh D, Courtneidge SA, McWeeney SK and Kulesz-Martin M: Induction of anaplastic lymphoma kinase (ALK) as a novel mechanism of EGFR inhibitor resistance in head and neck squamous cell carcinoma patientderived models. Cancer Biol Ther 19(10): 921-933, 2018. PMID: 29856687. DOI: $10.1080 / 15384047.2018 .1451285$

25 Perrone F, Bossi P, Cortelazzi B, Dagrada GP, Paielli N, Licitra $\mathrm{L}$ and Pilotti S: Absence of ALK and MET alterations in head and neck sarcomatoid carcinoma. Oral Oncol 58: e4-5, 2016. PMID: 27262592. DOI: 10.1016/j.oraloncology.2016.05.015

26 Kim SM, Kim MJ, Jung HA, Sun JM, Choi YL, Ko YH, Park $\mathrm{K}$, Baek CH, Son YI and Ahn MJ: Presence of anaplastic lymphoma kinase translocation in sarcomatoid carcinoma of head and neck and treatment effect of crizotinib: A case series. Head Neck 37(5): E66-9, 2015. PMID: 25270523. DOI: $10.1002 /$ hed .23884

27 Gonzales CB, De La Chapa JJ, Saikumar P, Singha PK, DybdalHargreaves NF, Chavez J, Horning AM, Parra J and Kirma NB: Co-targeting ALK and EGFR parallel signaling in oral squamous cell carcinoma. Oral Oncol 59: 12-19, 2016. PMID: 27424178. DOI: $10.1016 /$ j.oraloncology.2016.05.007
Received March 13, 2019

Revised April 9, 2019

Accepted April 10, 2019 